\title{
Agreement in Persian *
}

\author{
Ahmad R. Lotfi (Esfahan)
}

\begin{abstract}
This article investigates agreement as a number marking mechanism in Persian. The mechanism differs from number marking on nominals in that with an inanimate plural subject, the SG verbal ending signals a collective conceptualization of the experience where the members of the group are considered together as a single unit. The PL ending, on the other hand, signals a distributive conceptualization where the entities are individuated; hence, they are considered to be dispersed over space, or distinct in sort or time. Autonomy - whether the entity is conceived of as governing the course of events or not - seems to underlie the choice between SG and PL.
\end{abstract}

\section{$1 \quad$ Introduction}

Despite the recognition of the logical and linguistic complexities inherent in the study of number (Jespersen 1924; Lyons 1968; Corbett 2000; Sharifian/Lotfi 2003), this grammatical category is still among the most underestimated ones. Verb-argument agreement and how it relates to semantico-cognitive aspects of our mental life are left even less explored in our surveys. The article is intended to shed light on the yet unexplored complexity of agreement phenomena in Persian, and show why verb-argument agreement deserves a deeper semanticocognitive analysis.

I begin with the number values, and plurality marking mechanisms in Persian. Then verbargument agreement is explored in terms of the differences it makes between collective and distributive interpretations of events. Comparative data from classical and modern prose are analyzed in order to shed light on the use of SG/PL in Persian. I argue that it is the feature autonomy that makes the language 'split' in this respect. A revised version of the Animacy Hierarchy originally formulated by Forchheimer 1953, Smith-Stark 1974, Silverstein 1976, and Corbett 2000 comes up next. The theoretical implications of the study for language research conclude the article.

\section{$2 \quad$ Number in Modern Persian}

\subsection{Number values}

The language has three number values: general, singular, and plural. As Figure 1 indicates, the general number is combined with the singular resulting in a general/singular versus plural system.

\footnotetext{
* I would like to thank my anonymous reviewers for their careful reading of the first draft of this article, and also their most valuable comments on my analyses of the phenomena under study here. All shortcomings remain solely mine.
} 


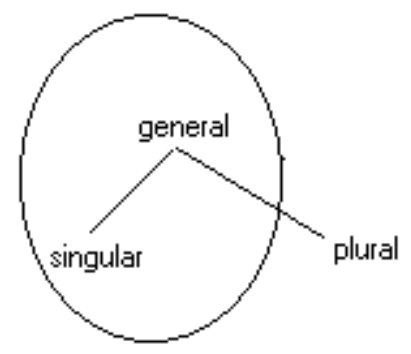

Figure1: Persian system with general/singular versus plural

The general number marks the nominal with singular inflection (zero inflection) in order to generically specify the entities as one single category. As such, the form does not specify the number of entities in the real world but what is shared or typical of a whole class of things. The impossibility of a potential definite/indefinite article may serve as a diagnostic for distinguishing between general and singular:

(1)

a. Inja ye gorg hast. (singular)

here a wolf is

"There's a wolf here."

b. Inja gorg hast. (general)

here wolf is

"There is a wolf/are some wolves here."

\subsection{Plurality marking mechanisms}

\subsubsection{Nominal marking}

Persian employs two mechanisms - nominal marking and verb inflection (verb-argument agreement) - in order to mark plurality. The singular is not marked on the nominal, which is in agreement with the generally accepted contention that "the singular is the unmarked number as compared to the plural" (Corbett 2000:17). In general, marking of the nominal for plurality does not seem to 'split' the language: plural marking is not sensitive to the semantic category to which the nominal belongs. The only exception is the contrast between two plural suffixes "-ha" and "-an" in formal/literary varieties of the language where "-ha" is possible for all classes of nominals while "-an" is reserved only for animates (Table 1). In informal varieties of the language, however, the suffix "-an" is quite rare. In these varieties, the generic PL marker "-ha" (usually reduced to "- $a$ ") replaces both.

\begin{tabular}{|l|l|l|}
\hline & \multicolumn{1}{|c|}{ Animates } & \multicolumn{1}{c|}{ Inanimates } \\
\hline -ha & $\begin{array}{l}\text { mard } h a(\text { men), zan } h a(\text { women}), \\
\text { shirha (lions), deraxtha (trees) }\end{array}$ & $\begin{array}{l}\text { dard } h a \text { (pains), tanha (bodies), } \\
\text { tirha (arrows), raxtha (garments) }\end{array}$ \\
\hline -an & mardan, zanan, shiran, deraxtan & $*$ dardan, *tanan, *tiran, * raxtan \\
\hline
\end{tabular}

Table 1: Plural markers for animates and inanimates in formal/literary Persian

As shown below in Figure 2, this is in perfect harmony with the Animacy Hierarchy - the idea that various languages 'split' at different points along with a hierarchy of animacy (Forchheimer 1953; Smith-Stark 1974; Silverstein 1976; Corbett 2000). According to Smith- 
Stark (1974), plurality splits a language if "it is a significant opposition for certain categories but irrelevant for others" (1974: 657). He claims that nouns in Georgian, for instance, are split, and that the division there occurs between animates and inanimates: For a plural subject denoting an animate in Georgian, the verb will be marked plural. But it will be singular if the plural subject denotes an inanimate. Likewise, the plural morpheme "-an" splits Persian nominals, and the division is between animates and inanimates:

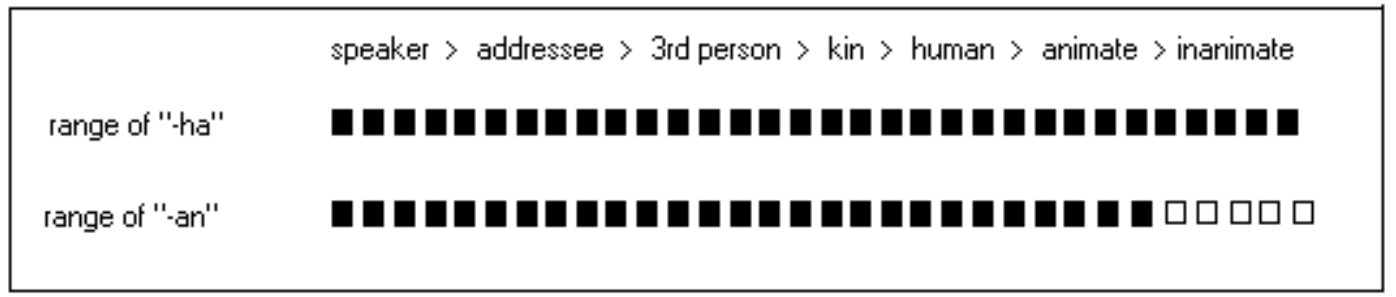

Figure 2: Range of plural marking suffixes on nominals in literary Persian

The semantic categories at the top of the figure are ordered in an implicational hierarchy so that if an element, e.g. the plural suffix "-ha", is permitted to mark a nominal somewhere on the hierarchy (for instance a noun belonging to the category human), then it must also be permissible for the suffix to mark a nominal belonging to a category to the left of human (e.g. kin) but not necessarily one to its right side such as animate. Persian "-ha" and "-an" apply in harmony with this hierarchy, because there is no break ${ }^{1}$ in the application range for either of these two suffixes. Moreover, the split associated with "-an" occurs at the right end of the hierarchy. ${ }^{2}$ As such, evidence from these plural suffixes in Persian lends support to the universality of the Animacy Hierarchy.

\subsubsection{Verb inflection}

Verbs are marked for both plural and singular. As shown in Table 2, the choice of the right suffix in either case depends upon the person feature of the subject. Third person singular is the bare form.

\begin{tabular}{|l|l|l|l|}
\hline & $\mathbf{1}^{\text {st }}$ & $\mathbf{2}^{\text {nd }}$ & $\mathbf{3}^{\text {rd }}$ \\
\hline Singular & $\begin{array}{l}\text { raft-am } \\
\text { "I went" }\end{array}$ & $\begin{array}{l}\text { raft-i } \\
\text { "you went" }\end{array}$ & $\begin{array}{l}\text { raft } \\
\text { "s/he went" }\end{array}$ \\
\hline Plural & $\begin{array}{l}\text { raft-im } \\
\text { "we went" }\end{array}$ & $\begin{array}{l}\text { raft-id (/-in) } \\
\text { "you went" }\end{array}$ & $\begin{array}{l}\text { raft-and (/-an) } \\
\text { "they went" }\end{array}$ \\
\hline
\end{tabular}

Table 2: Verb inflection for "raftan" (to go)

(Forms between parentheses are informal variants.)

\footnotetext{
${ }^{1}$ A break would look like (... split that does NOT extend to either end-points of the hierarchy. This would be understood as saying "only for the category/categories above the break (but not for those before or after it), the suffix cannot mark the nominal as plural." In Fig. 2, on the contrary, the split occurs at the right end of the hierarchy. Then there is no break in either of application ranges.

2 It would be semantically odd if the split in the application range of "-an" had occurred at the left end of the hierarchy given the implicational arrangement of the semantic categories at the top of the figure. In other words, a language with a plural suffix marking speaker but NOT addressee (also one marking animate but neither human nor inanimate) would violate the Animacy Hierarchy.
} 
Like nominal marking in literary Persian (see 2.2.1), verb inflection in Modern Persian splits nouns. As shown in examples below, for plural animate subjects, the verb will be marked plural. For plural inanimates, on the other hand, the verb may be singular:

(2)

a. Marda umad-an xune. men come-PAST-PL home

"The men came home."

b. Ketaba bad forush raft.

Books bad sale go-PAST-SG

"The books sold badly."

This is compatible with Smith-Stark's observation concerning verb inflection in Georgian (see 2.2.1). Once more, the Animacy Hierarchy is respected in that the division is between animates and inanimates at the right end of the hierarchy ${ }^{3}$ (cf. Figure 2).

\subsection{Interpretation: Collective v. distributive}

With an inanimate plural subject, the SG verbal ending signals a collective interpretation ${ }^{4}$ of the event with members of the group considered together as one single unit. The PL ending, on the other hand, signals a distributive reading where the entities are individuated; hence, they are considered to be dispersed over space, or distinct in sort or time:

(3)

a. Sosis-a suxt (na lubiaha). (Collective)

sausage-PL burnt-SG not bean-PL

"The sausages burnt (not the beans)."

b. Sosis-a suxt-an. (Distributive)

sausage-PL burnt-PL

"The sausages burnt."

The collective analysis of the event indicates that sausages (but perhaps not, say, beans) were all burnt together while frying them in the same pan and at the same time, or that they are considered as one single thing, e.g. a dish of sausages.

\footnotetext{
${ }^{3}$ For a revised version of the hierarchy, and how verb inflection in Persian splits nouns on it, see Figure 7.

4 That such nouns are interpreted collectively does not mean they are necessarily collective nouns themselves. I understand a collective noun as one inherently marked collective in the lexicon, e.g. galle (herd), shora (council), or team (team). Such nouns refer to a group of individuals without being marked with a plural morpheme. My collective interpretation, on the other hand, is context sensitive and morphologically plural. The members of the group in the latter are inanimate.
} 


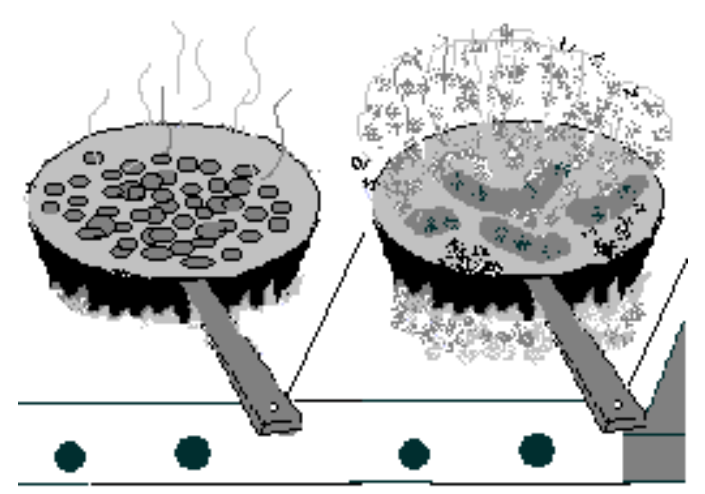

Figure 3: Collective interpretation of the event (sosisa suxt)

The distributive analysis, on the other hand, implies that the burning of each sausage is viewed independently of others. Now they may be in different pans, getting fried at different times, or to be served separately.

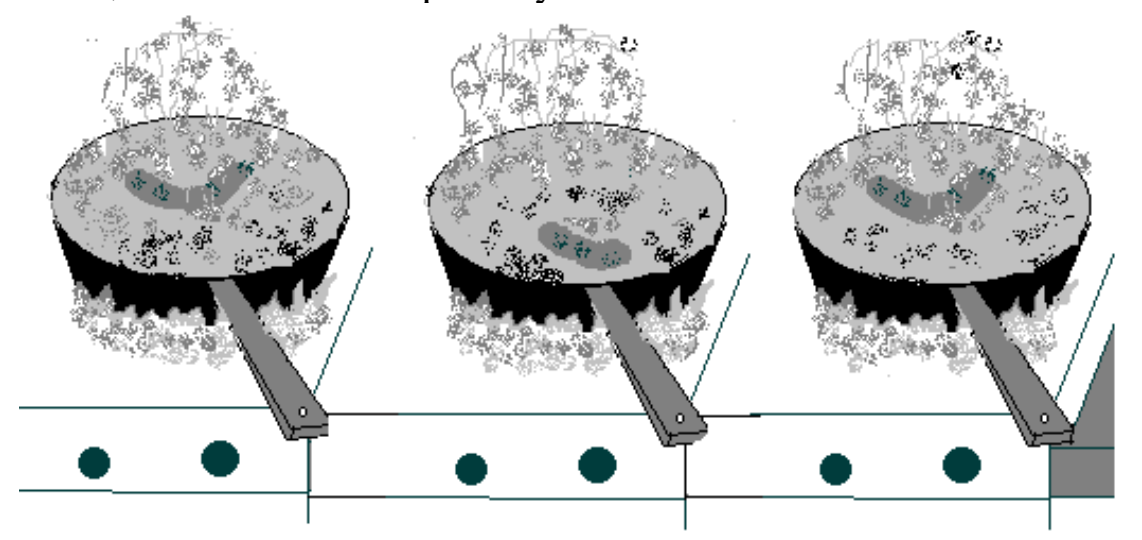

Figure 4: Distributive interpretation of the event (sosisa suxtan)

Even when frying them all in one pan and at the same time, both collective and distributive interpretations are possible depending upon the speaker's conceptualization of the event, i.e. whether the speaker conceives of them as one single thing, or as individuated ones. In a sense, then, the intended interpretation is subjective. For one single event, the speaker may decide to conceptualize the entities involved as unitary or individuated. In such cases, interpretation is a matter of decision.

How Persian has come up with its number system is not an easy question to answer. The history of collective/distributive interpretation via SG/PL is doubly shrouded in mystery. Fortunately, the language has been well documented for the past two millennia, which makes the search for the source of this functioning of the system a reasonable scientific endeavour. In Section 3 below, I take a first step towards such a conceptual analysis of the number system in Persian. In this limited study, however, I could not begin earlier than the $11^{\text {th }}$ century AD because I found the language of the prose written earlier than that too obscure to analyse. The study is comparative in that I compare classical and modern prose in Persian with regard to plural marking as specified earlier.

\section{Comparative data: Classical v. modern prose}

The Persian agreement data that I comparatively analyse in this section come from two eras in the history of the language that are distinct in their lexical, syntactic and stylistic preferences, 
namely (a) Persian classical prose dating back to the $11^{\text {th }}-14^{\text {th }}$ centuries AD including Monshi's translation of Kelileh va Demneh ( $11^{\text {th }}$ century) from Arabic, which is a long animal fable written originally in Sanskrit, Rumi's literary work Fih-e Ma Fih $\left(13^{\text {th }}\right.$ century) on Islamic philosophy and mysticism, and Tusi's Asas al-Eghtebas $\left(14^{\text {th }}\right.$ century) in logic, and (b) journalistic texts ${ }^{5}$ selected from the Iranian daily Ettela'at (1939-1941, 2005). The logic behind the selection of these eras is that agreement marking in Persian seems to have changed drastically over this period of about 1000 years. The analysis is expected to shed light on the question of SG/PL association with such semantic features as animacy and autonomy in Persian. Moreover, the subtle differences between modern Persian prose today and that written about 60 years ago seem to signal the latest developments Persian has been through with regard to agreement marking ${ }^{6}$.

From either of the classical prose works mentioned above, a corpus of 200 paragraphs was randomly selected amounting to a total of 10,753 finite clauses. For the journalistic texts, whole articles (20 in total) were taken as the corpora amounting to 5,346 finite clauses. All sentences in both classical and modern corpora with a plural nominal as the subject were analysed in terms of SG/PL verbal inflection. In a number of sentences from the classical corpora, verbs (mainly quasi-/copulas) were left implicit:

Dar vay shekari besyar va extelaf-e sayadan-e anja motavater. (KvD: 157)

in it game many and disputes-of hunters-of there frequent

"There were many game animals there, and hunters disputed over the place frequently."

Such sentences were discarded in the analysis as they marked plurality only on subject nominals.

\section{1 [+ Animate, +/- Human] plural subjects}

Apart from three finite clauses in the Kelileh va Demneh corpus, all other clauses in both classical and modern prose corpora are consistently inflected with PL as long as the plural subject is an animate human/non-human entity. The exceptional cases are given below with the plural subject in bold type, and the relevant verb in italics:

\footnotetext{
5 A reviewer raises the issue that the classical works examined here are literary texts (mostly fictions). Then a comparison of classical and modern prose in Persian would be more meaningful if the modern prose corpora also included modern literary texts especially fictions. Although I agree with this statement in principle, I'd originally decided not to include such works in the study on the grounds of research scope: Modern writers in this country are divided among themselves concerning both the status of classical literature and its language in the modern society. Any corpus representing major literary styles in Modern Persian would be quite huge in size. Some Iranian writers practice a literary style closer to Persian classical prose, and express their dissatisfaction with the journalistic style of writing on the grounds that journalistic prose is too much distanced from literary styles of the glorious past of Persian literature, hence 'ungrammatical' in certain respects. Some others, on the other hand, practice colloquialism as they think literature must be a reflection of natural ordinary speech. To address the issue within the limited scope of this study, a brief review of random literary samples from Faslname-ye Zenderud (a quarterly journal on Persian modern literature) is given in Appendix 1. No claim can be made, however, to the representativeness (nor to the literary quality) of the texts examined. The journal is in sympathy with a literary tradition known as the Esfahan Circle. The tradition is associated with the finest works in modern fiction done by, among others, the late Iranian writer Hushang Golshiri.

6 In this study, I focus on the written varieties of the language. My spoken data come from the local variety spoken in Esfahan - a major industrial city in central Iran. It is to be borne in mind that contrary to Written Persian and also some local spoken varieties of the language like Esfahani, many speakers, especially the younger ones, tend to do things differently at least once they communicate informally. In Spoken Tehrani Persian (Farsi), for instance, speakers tend to do away with SG verbal inflection for plural subjects, and use PL for both animates and inanimates.
} 
(5)

a. Dar abgiri se mahi bud.

in pool-INDEF three fish was

"There were three fish in a pool."

b. Dar mian-e zaghan panj zagh bud be fazilat-e ray mazkur. in among crows five crow was to superiority-of wisdom mentioned "Among the crows, there were five renowned for their superior wisdom."

c. An do bat ke az pas-e malek bexastand those two duck that from back-of king fly-PAST-PL

va pish-e $\mathrm{u}$ forud amadand do sar asp bashad

and front-of he land come-PAT-PL two head horse is

ke az jahat-e shah-e Kalenjar hedye avarand.

that from direction-of king-of Kalenjar gift bring-PAST-PL

"Those two ducks flying after the king and landing before him are two horses brought to the King of Kalenjar as a gift."

Apparently, the point of split in such cases had moved rightward on the Animacy Hierarchy from [+Animate] to [+Human]. The verb in all these three instances is a 'to be' expression, and the head noun is preceded by a number. The sentence $(5 \mathrm{c})$ is quite interesting in this respect: for one and the same plural nominal, i.e. "those two ducks", the verbs "fly" and "land" are marked plural while "be" is left singular. This suggests that the way the author conceived of the situation - reflected in the verb type he used - was a decisive factor in his implementation of SG/PL. Apparently, when a non-human animate was conceived of as a non-agent/non-actor, SG could be used to "de-animate" the entity in question. Based on this specific example, I hypothesize that in cases where the subject was conceived of as having the capacity to act out of its own volition, e.g. birds' flying or landing, the verb was less likely to be marked as singular. The findings on SG/PL and the conceptualization of events in classical and modern prose suggest that this hypothesis is on the right track. See Section 4 below for more on this.

\section{1 [- Animate] plural subjects}

\subsubsection{The classical prose corpora}

The treatment of inanimate plural subjects seems to be less consistent than that of animates across (and sometimes within) different eras in the history of the language. As far as the corpora analysed for this study are concerned, Monshi's Kelileh va Demneh, and Tusi's Asas al-Eghtebas showed consistent use of singular inflection for all verbs as long as the subject was a plural inanimate entity:

(6) From the Kelileh va Demneh corpus

a. Darha-ye ruzi bar man goshade gasht.

doors-of sustenance on me open become-PAST-SG

"The doors of sustenance were opened to me." 
b. Baranha motavater shod.

rains frequent become-PAST-SG

"Rainstorms became frequent."

c. Ruzha bar an gozasht.

days on it pass-PAST-SG

"Days passed afterwards."

(7) From the Asas al-Eghtebas corpus

a. Ma'ani ba'zi daxel oftad dar ba'zi. meanings some inside fall-PRES-SG in some "Some meanings are included in others."

b. Chizha az chahr guneh xali nabashad. things of four kind empty NEG-be-PRES-SG "Things are of no kind but four."

c. Absar va muy va dandanash zayel shavad. eyes and hair and tooth-his disappeared become-PRES SG "His eyes, his hair, and his teeth will be gone."

It follows that Persian earlier prose was split on the Hierarchy of Animacy somewhere between animates and inanimates ${ }^{7}$. The possible conceptual differences among inanimates did not amount to plurality marking of verbs, at least not in such prose works as Monshi's and Tusi's.

Rumi's Fih-e Ma Fih is also characterized with SG verbal inflection for plural inanimates. The following examples are typical of the sentences in the Fih-e Ma fih corpus:

(8) From the Fih-e Ma fih corpus

a. Agar in daricheha nabashad ... . if these windows be-PRES-SG

"If there are no such windows ..."

b. Asmanha ... natavanest pezroftan. skies not-could-SG accepting

"The skies couldn't shoulder the responsibility."

c. Jebal ma'nanha-ye gunagun midahad. mountains mines-of various gives "Mountains offer various mines."

On the other hand, we can also find cases of apparent anomaly where PL inflection is used for plural inanimates:

(9) Apparent anomalies in the Fih-e Ma fih corpus

a. Asmanha va zaminha mosaxar-e hokm-e veyand.

skies and grounds conquered-of verdict-of he-be-PRES-PL

"Skies and grounds are conquered by His verdict."

7 Compare this with the range of plural marking suffixes on Persian nominals in Figure 2 above. 
b. Ma'aden-e zar-o noghre va la'l-o yaghut zaher mishavand. mines-of gold-and silver and ruby-and topaz apparent become-PRES-PL "Mines of gold and silver and those of ruby and topaz are revealed."

c. Andishha morghan-e havaiand. thoughts birds-of air-be-PRES-PL "Thoughts are (like) the birds in the sky."

d. Sefat-e to ashegh-e haghand. attributes-of you lover-of truth-be-PRES-PL "Your attributes are lovers of the truth."

e. Har gah ke xialat az mian barxizand, haghayegh ruy nemayand. each time that phantoms from middle stand up truths face show "Once phantoms fly away, truths uncover their face."

Even here, however, SG and PL are not in free variation at all. In (9a-b), like many other cases with plural inanimates and PL verbal inflection in this corpus, the subject of the sentence is a conjunction of some other plural nominals. Since either of these conjoined elements is a plural inanimate treated in isolation as a single entity, e.g. "skies" in (8b), it is safe to say that PL in such cases reflects the status of the subject as a conjunction of two or more nominals too heterogeneous to conceive of as a single entity; hence PL marking.

Sentences (9c-e) are then particularly significant to my analysis of SG/PL in Persian because they do not contain any conjunction phrases. Even here, however, the occurrence of PL is far from being unsystematic. Careful readers have already noticed that the plural inanimate is personified in either case. The author conceived of each as an entity capable of volition - a property normally associated with animates, particularly human beings. Inanimates as volitional autonomous creatures are compatible with a mental image where such entities control (fully or even partially) the relevant course of events. They are not doomed to perform collectively anymore as they "make their own mind" even when targeting at one and the same goal. This makes SG irrelevant, and PL prevails. As far as the Animacy Hierarchy is concerned, the line of division between SG and PL has already begun to move rightward into the realm of inanimates. Conceived autonomy/volition rather than mere animacy seems to split the language now.

\subsubsection{The modern prose corpora}

Like classical prose texts reviewed above, the texts selected from the Iranian daily Ettela'at (1939-1941) openly use the SG verbal inflection for inanimates:

(10) From the Ettela'at corpus (1939-1941)

a. Maghazeha va dokanha baz shod, shops and stores open become-PAST-SG

va bazarha jarayan-e ma'mooli-ye xod ra az sar gereft. and markets process-of normal-of self DO-particle from start get-PAST-SG

"Shops were opened, and the markets began their normal activities once more." 
b. Galleha-ye anha dar in naghl-o enteghal az-bein-raft. herds-of they in this transfer destroy-PAST-SG

"Their herds were destroyed during the transfer."

c. Mozakerat be marhale-ye roshani reside ast.

talks to stage-of clear come be- PRES-SG

"The talks have reached a clear stage."

Despite that, for those inanimate entities normally associated with human beings, such as cars, buses, and governments, the PL inflection is consistently preferred:

(11) Apparent anomalies in the Ettela'at corpus (1939-1941)

a. Otobus-ha-ye shahri dar raft-o amad budand.

Buses-of urban in traffic be-PAST-PL

"Buses were moving around in the city streets."

b. Koliye-ye vasayet-e naghliye bayad foran be taraf-e rast-e all-of media-of transportation must immediately to side-of right-of

jade rafte va tavaghof-nemayand. road go and stop-PRES-PL

"All transportation media must immediately go to the right side of the road and stop."

c. Tamam-e doval ke ba Iran ravabet darand ... all-of governments that with Iran relations have "All governments that have (diplomatic) relations with Iran ..."

d. Cinemaha niz dayer mibashand.

Cinemas also open be-PRES-PL

"Cinemas are also open."

Clearly, that such inanimates are associated here with men as volitional/autonomous entities makes PL inflection necessary. Although the inanimates are not personified as in Rumi's, they are raised now to the status of (human) animates via the intervention of the people in control. Once more, it is the speaker's mentality in such terms as their conception of events and entities that determines the distribution of SG/PL.

Likewise, more recent prose texts randomly selected from the daily Ettela'at (2005) continue to employ SG for inanimate plurals as long as they are thought of as collective entities with no autonomy of their own:

(12) From the Ettela'at corpus (2005)

a. Siasatha-ye kalan-e keshvar ba taghyir-e reisjomhoori avaz-nemishavad. policies-of major-of country with change-of presidency change-not-PRES-SG "The country's major policies are not altered once a new president is elected."

b. Tahdidha va tote'eha-ye ghodrat-talaban-e jahan ta'siri naxahad dasht. threats and conspiracies-of power-seekers-of world effect not-will-SG have "The threats and conspiracies of the world powers will have no effect." 
c. Kartha-ye pardaxt-e bank baraye tamam-e senin tarahi shode ast. cards-of payment-of bank for all-of ages design become be-PRES-SG "Bank cards are designed for use of all age groups."

On the other hand, once the inanimates are conceived of as autonomous entities - whether associated with men in control of them or not - the verb may be inflected as plural:

(13) Apparent anomalies in the Ettela'at corpus (2005)

a. Ban Barz, Ban Boor, Sabziabad, ..., mahaleha-ye hashiyeyi

Ban Barz, Ban Boor, Sabziabad, ..., quarters-of marginal

mibashand ke hodud-e 540 hektar masahat darand.

be-PRES-PL that about-of 540 hectares area have-PRES-PL

"Ban Barz, Ban Boor, Sabziabad, ..., the quarters located on the outskirts of the city amount to 540 hectares in area."

b. Rasaneha dar tose'e-ye ebtezal naghsh-e mo'aseri ifa-kardeand. media in spread-of immoralities role-of effective play-PRES-PL "The media have played an important role in the spread of immoralities."

c. Sayer-e kartha-ye pardaxt ghabeliat-e daryaft ta saghf-e 200,000 Tms

Other cards-of payment capacity-of getting till ceiling-of

ra dara-hastand.

do-PART have-PRES-PL

"Other bank cards have the capacity of getting money to a maximum of 200,000 Tms."

\section{Discussion}

In this section, I argue for a conceptual relationship between (a) the interpretation of an event (collective v. distributive) and (b) how entities are conceived of (autonomous v. nonautonomous). Although the general discussion is to be understood in reference to the comparative data discussed earlier in Section 3, the findings also have a bearing on theories of number and interpretation in general.

\subsection{Autonomy and interpretation}

The Persian data examined in Section 3 suggest that the semantics of number involves such components as count, autonomy, animacy, and human. These components may be organized in a hierarchy of semantic necessity so that the presence of a feature higher in the hierarchy implies the presence of those of lower conceptual ranks: 


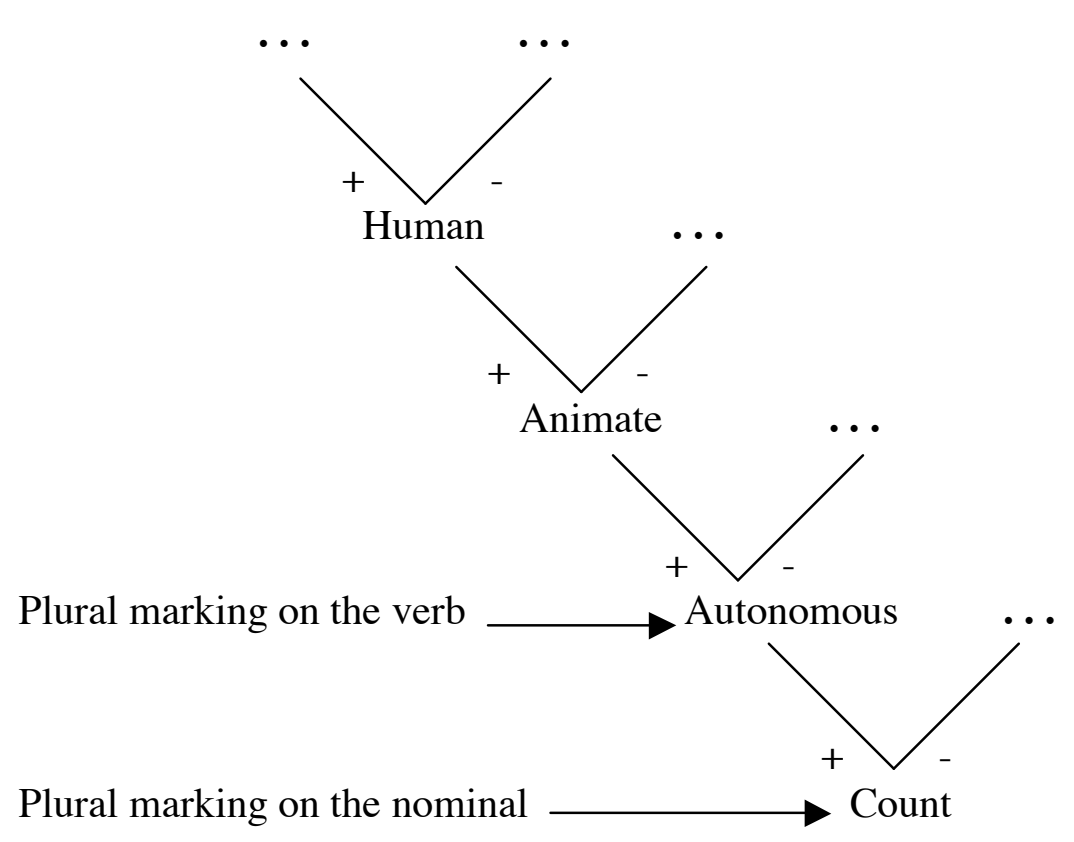

Figure 5: A semantic hierarchy for number marking in Persian

If the entity is animate, it is inevitably countable but not necessarily human. The SG/PL inflection of the Persian verb serves as a marker of this semantic hierarchy. The data suggest that for nominals in both classical and modern prose, PL applies at the root of the hierarchy so that if the entity is countable, it can be marked plural. For verbs in classical prose, the language is generally split at animacy so that if the animate subject is plural, the verb that follows will be plural, too. In contrast, if the plural subject is inanimate, the verb will be marked singular. For verbs in modern prose, on the other hand, PL applies at a higher level, namely, autonomy (by which I mean the entity is conceived of as governing the course of some relevant event it passes through (so that)/(as if) it acts out of its own 'volition'): if each member of the group is conceived of as [+ Autonomous], then PL will mark plurality on the verb.

This autonomy, however, is the reflection of what the mind assumes subjectively rather than the objective course of events in the outside world. This is in line with a Langackerian understanding of semantics where "[m]eaning is ... sought in the realm of cognitive processing rather than residing in objective reality" (Langacker 1990:61).

We might conceive of clouds as autonomous living things (even intelligent creatures with a capacity of volition) that float in the sky or conceal the sun as human beings draw a curtain or open a window. Personification of non-living things is a commonplace experience of the human mind. Such conceptualizations of inanimate entities are not always as dramatic as the use of psych-verbs for Alice-in-Wonderland entities. In more moderate cases, it may be confined to the use of PL verbal ending for plural inanimates in Persian. The cognitive experience is depicted in the diagrams below in Figure 6.

In Diagram (a), there are three instances of X, say stones rolling down a hill, or sausages burning in a frying pan, which are conceived of as [-Autonomous]: the stones roll down the hill under the influence of gravity with no influence of their own on the course of the event. Similarly, the sausages in the same pan all burn with no option for one to assume a different course of events. Consequently, SG is used to mark uniformity of action in such cases. As depicted in Diagram (b), it is also possible to think of the same event as what either of the stones does individually. We ignore the gravity, and assume that either of them rolls down by 
its own 'free will'. For sausages, we may ignore the cause of burning, and focus on the changes of state individuated sausages experience instead, which is magnified when each sausage is fried in a different pan. If so, PL will be preferred.

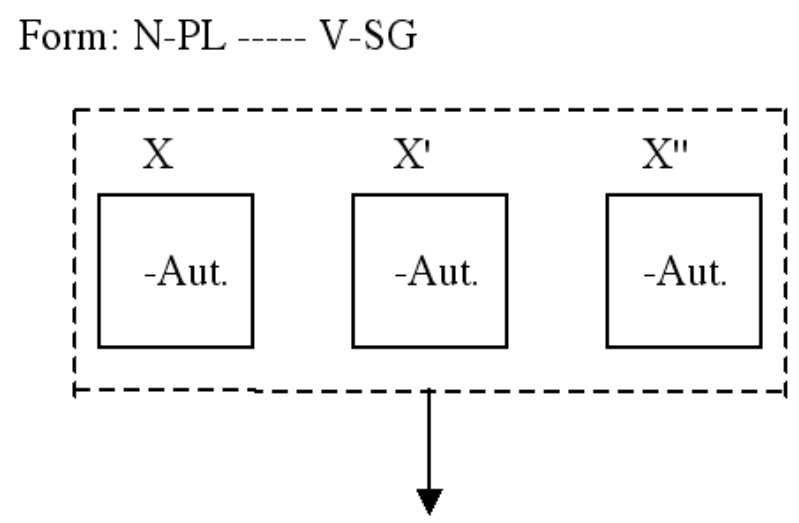

EVENT

(a) Collective experience ("Sosisa suxt")

Form: N-PL ------ V-PL

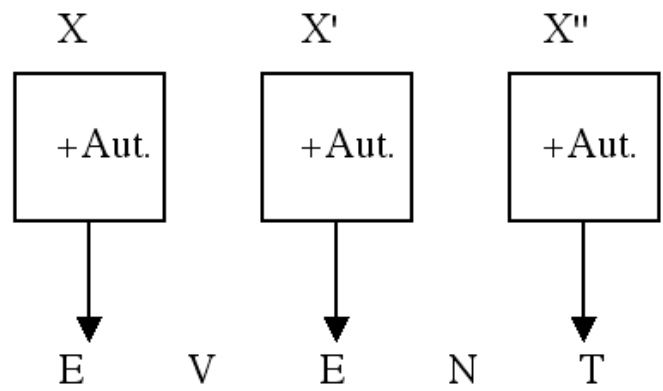

(b) Distributive experience ("sosisa suxtan")

Figure 6: Cognitive experience of autonomy

To summarize, for individual entities conceived of as non-autonomous elements that participate in an event impersonally, Persian speakers use SG on the verb to signal collectivity. On the other hand, when the entities are conceived of as autonomous elements (each of them participating in the event volitionally), PL is used to signal distributiveness. For animates, autonomy is conceptually granted (see the hierarchy in Figure 5 above). For inanimates, on the other hand, autonomy is left indeterminate, and, as a result, either a question of the nature of the activity itself (e.g. inanimate machines controlled/designed by animates), or a matter of decision (e.g. burning sausages or rolling stones).

\section{Conclusions}

In this final section, I briefly examine the theoretical implications of this study for research on the Animacy Hierarchy and iconicity research. Although neither of these fields of study can 
be approached at any depth in one single article, I show how a convergence of these two sheds light on the complexity of number.

\subsection{The Animacy Hierarchy}

The Animacy Hierarchy formulated by Forchheimer (1953), Smith-Stark (1974), Silverstein (1976), and Corbett (2000) is in need of revision in order to capture the evidence from number marking in Persian. Without such a revision, it simply misses the differences in the application of SG and PL in verb-argument agreement in Persian. A revised version of the Animacy Hierarchy for number marking on verbs is represented in Figure 7 below where $\square$ indicates collective number and $\mathbf{D}$ the plural.

\begin{tabular}{l}
$1>2>3>$ kin $>$ human $>$ animate $>$ autonomous $>$ non-autonomous \\
$\begin{array}{l}\text { range of number marking on } \\
\text { nominals } \\
\begin{array}{l}\text { range of number marking on } \\
\text { verbs }\end{array}\end{array}$ \\
\hline
\end{tabular}

Figure 7: Number marking in Modern Persian

As no provision was made in the original hierarchy to cover the distribution of SG and PL verbal endings in Persian, the features autonomous and non-autonomous were simply neglected in favour of one single term - inanimate. This, at best, would dismiss the differences between SG and PL as optional variation in agreement for inanimates, which is both inaccurate and negligent of the conceptual regularity with which SG and PL verbal endings are distributed in Persian.

Even the revised hierarchy proposed here is at best only descriptively more adequate in telling us where nominals are split in Persian. The question of why it is SG that is associated with collectivity and PL with distributiveness (and not, say, vice versa) is still swept under the rug. The following subsection on the relevance of agreement phenomena to iconicity research may be more revealing in this respect.

\subsection{Iconicity}

SG/PL-marking in Persian is of direct relevance to iconicity research typically concerned with the direct/non-arbitrary/non-symbolic relation between meaning and form. As investigations of verb morphology by Haiman (1985) and Bybee (1985) reveal, the ordering of markings with respect to a verb stem is most often iconic. For instance, in many languages, aspect markers are closer to the stem than tense markers because aspect is conceptually more tightly bound to the verb. The direct correlation between verb morphology and number marking as collective/distributive in Persian is likewise a reflection of the conceived autonomy of entities in action. When a Persian speaker says 'the sausages is burning', they still conceive of sausages as multiple entities in essence but collectivized in action. Likewise, for 'the sausages are burning', they are individuated with regard to what they do. ${ }^{8}$ As a verb is the unmarked linguistic realization of an action or event, the proximity between the verb and the conceived

\footnotetext{
8 They were already individuated as distinct entities through plural marking on the nominal.
} 
autonomy of members of a group in action makes verbs natural markers of collectivity and distributiveness. ${ }^{9}$

Number marking in Persian is iconic in a second sense. As the diagrams in Figure 6 above depicted, the collective and SG are directly related in that both have the concept of oneness in common. With an SG marked on the verb, the plural number in the subject position assumes singularity in interpretation as all members of the group are treated as one single whole with no autonomy of their own. The plural marking on the nominal and the SG on the verb now signal different things simultaneously: while the SG implies the solidarity of the group with its members sharing a common fate, the plural marking on the nominal emphasizes the individuality of the members within a holistic entity. Similarly, PL and the distributive are directly related because they both point towards multiplicity and plurality. As such, the notion of group ceases to have any significance as the members are individuated both within and without the nominal: entities are both distinct in what they are, and autonomous in what they do.

Since iconic relations are non-arbitrary, there is a chance that the restrictions on the phenomena outlined above are universal in scope as long as they are relevant to the speaker's modes of conceptualization. That is, human beings may decide NOT to view collectivity and distributiveness at all, and if they do, not necessarily in terms of autonomy. ${ }^{10}$ Anyway, if they do view entities as collective or distributive, and if autonomy is their criterion to that end, marking SG/PL on the verb is an immediately available linguistic resource. Although agreement facts in English are different from those in Persian, the languages are similar enough once collectivity and autonomy are in perspective: in both (14a) and (14b) below, the nominals are singular in morphology and collective in conceptualization. The verb is marked plural in (14a) but singular in (14b).

a. The cattle were in the shed.

b. The forest ${ }^{11}$ was in the north.

\footnotetext{
${ }^{9}$ This makes it also relevant to see if the verb type, tense, and aspect specifications of the event play any role in the speaker's preferences for SG and PL. For many speakers of Persian, for instance, PL seems to be more frequently employed once the verb is expressed with a future tense. Apparently, autonomy in action is more viable when the course of events has not come to an end yet.

${ }^{10}$ Either of these decisions may be formed or informed by culture.

${ }^{11}$ A reviewer questions the status of "forest" as a collective noun: "Forest in my view is not collective - it might be a collection of trees, but that's in the nature of the forest, it doesn't mean that forest is used collectively." Firstly, I have focused throughout the article on the collective interpretation of a noun, which is NOT the same as saying the noun is necessarily a collective noun: Persian inanimate plural subjects may or may not be interpreted collectively depending upon SG/PL ending on the verb that follows. This doesn't mean all these nouns are to be labelled as collective nouns, which are inherently plural out of any context, and (significantly) plural in meaning without any plural marking on the nominal. Moreover, that collections are not always collective nouns may be still captured in terms of autonomy: for an X (X the collection of Ys), the mind resists interpreting $\mathrm{X}$ as collective when $\mathrm{Ys}$ are radically deprived of conceptual autonomy in the context of $\mathrm{X}$. Under such circumstances, we see $\mathrm{Y}$ as an atom of $\mathrm{X}$ rather than $\mathrm{X}$ as a collective form of $\mathrm{Y}$. Then we may decide to see the relationship between a forest and its trees like that between a body and its cells, a library and its books, or a house and its bricks. Despite that, forests are still different from bodies, libraries, and houses. For bodies, libraries, and houses, $\mathrm{X}$ is more than a mere sum of Ys: a big pile of books crammed into a railway carriage to be transported from one library to another is hardly a library itself. In addition to books, we need shelves, desks, librarians, and (more abstractly) an organization of books according to the topic, the date of publication, etc in order to have a library. In this respect, a forest is conceptually closer to a herd of animals, i.e. a group of Ys near each other collectively termed X. Also of interest might be two related forms "wood" and "woods". The singular form is one single undivided entity on a par with a forest (though smaller in size, which is irrelevant here). It is in this conceptual context that the idiom expression "not see the wood/forest for the trees" comes into existence.
} 
One possible explanation is that trees in a forest are conceived of as less autonomous than cows and bulls in a herd as far as ruling the course of events is concerned.

Interestingly, (British) English permits both singular and plural verbs with a class of nominals (collective nouns) such as herd, class, committee, government, and team. According to Quirk/Greenbaum/Leech/Svartvik (1985), the difference between singular and plural verbal forms after the singular collective noun "reflects a difference in point of view: the singular stresses the nonpersonal collectivity of the group, and the plural stresses the personal individuality within the group" (Quirk et al. 1985: 316). As Quirk et al. point it out, "[t]he same principle extends to pronoun concord" (p.771):

a. The government are cutting their losses.

b. The government is cutting its losses.

Here again, "singular collective nouns have plural-verb concord in cases where the speaker thinks of the group as made up of separate individuals" (p. 771).

The iconic association of either form with the relevant mode of mental experience of the event is an attractive explanation for the semantic differences between SG and PL in English, too:
a. Our team is winning.
b. Our team are winning.
c. Our team are entering the field.

In (16a), we are thinking of our team as one single entity with the autonomy of its members subjectively diminished. In (16b) and (16c), on the other hand, team members are individuated in their winning of the game, or their entrance to the field.

As the findings of this study suggest, a conceptual explanation of the distribution of SG and PL in Persian is informed by the studies of semantic hierarchies and research on iconicity phenomena. Without either of them, the picture that emerges would be incomplete. Semantic studies give us the features around which speakers' decisions concerning the conceptualization of an experience takes shape: it is the feature [+/- Autonomous] that matters for Persian speakers in this respect. For speakers of other languages, it could be up to this or any other feature on the hierarchy to serve the purpose. In either case, the experience would be conceptualized differently. For Persian speakers (but not necessarily for speakers of other languages, too), it makes sense to treat autonomous and non-autonomous plural subjects differently. Then if the subject is an actor, and either of the members of the plural subject has got no autonomy to influence the course of events, the subject will to be interpreted collectively. Otherwise, the interpretation will be distributive. But why does the speaker deploy SG/PL ending on the verb to mark such interpretations? Iconicity seems to be the right answer to this question. Both SG and collectivity have the property of oneness in common. Likewise, PL and distributiveness share a notion of multiplicity. The SG/PL distinction marked on the nominal leaves no place for such manoeuvres as those discussed earlier because we already need them for marking the subject as singular or plural. Even if the subject is plural in meaning by itself with no use made of a PL-marker, i.e. it is a collective 
noun like "mellat" (people) in Persian, we still cannot signal a distributive interpretation with a PL on the noun itself because "mellat-ha" (peoples) would denote several groups of individuals instead of individual members of one single group. It follows that the SG/PL on the verb is the best formal candidate to signal such a conceptualization of the experience.

In this article, I argued that the conceptualization of an event organized around a plural inanimate noun as the subject is a function of a (Persian) speaker's perceived autonomy of each individual entity. Whether the noun is interpreted collectively or not is conceptually related to this feature of autonomy, and iconically realized as SG/PL in verb morphology. Agreement data from classical and modern prose in Persian supports such a view on number marking.

\section{References}

Bybee, Joan (1985): "Diagrammatic iconicity in stem-inflection relations." In: Haiman/John (ed.): Iconicity in Syntax. Proceedings of a Symposium on Iconicity in Syntax. Amsterdam.

Corbett, Greville G. (2000): Number. Cambridge.

Forchheimer, Paul (1953): The Category of Person in Language. Berlin.

Haiman, John (1985): Iconicity in Syntax. Proceedings of a Symposium on Iconicity in Syntax. Amsterdam.

Jespersen, Otto (1924): The Philosophy of Grammar. London.

Langacker, Ronald W. (1990): "Nouns and verbs." In: Langacker/Ronald W. (ed.): Concept, Image, and Symbol. The Cognitive Basis of Grammar. New York.

Lyons, John (1968): Introduction to Theoretical Linguistics. Cambridge.

Quirk, Randolph/Greenbaum, Sidney/Leech, Geoffrey/Svartvik, Jan (1985): A Comprehensive Grammar of the English Language. London.

Sharifian, Farzad/Lotfi Ahmad R. (2003): "'Rices' and 'waters'. The mass-count distinction in Modern Persian." Anthropological Linguistics 45: 226-244.

Silverstein, Michael (1976): "Hierarchy of features and ergativity." In: Dixon. Robert Malcolm Ward (ed.): Grammatical Categories in Australian Languages. Canberra.

Smith-Stark, Thomas Cedric (1974): "The plurality split." In: La Galy, Michael W./Fox, Robert A./Bruck, Anthony (eds.): Papers from the Tenth Regional Meeting. Chicago.

\section{Appendix 1:}

\section{PL/SG in samples from Persian modern literature}

Contemporary Iranian writers are divided among themselves concerning the question of the formal properties of literary language and style. As such, any corpus representing major literary tendencies in Modern Persian would be quite huge in size, which is beyond the scope of this study of number in Modern Persian. With no claim made to the representativeness of the texts (both in language and content), I here examine PL/SG verbal inflection in some recent literary prose (fiction and nonfiction both) published in one single issue of Faslnameye Zendehrud ${ }^{12}$ (22, Spring 2002). The quarterly is known to represent the Esfahan Circle in

12 It literally means "The Zendehrud Quarterly". The Zendehrud ("The Living River") crossing the City of Esfahan in Central Iran is a major tourist attraction in this country. The city is the $4^{\text {th }}$ most populated one in Iran. 
fiction writing. The small corpus here includes works by M. Bahar, F. Xansalar, S. Golshiri, A. Oxovat, and M. Kalbasi. Forty-three sentences with a plural inanimate as the subject were detected in the corpus, 31 (about $72 \%$ of the total) out of which used SG, and 12 (about $28 \%$ of the total) used PL as the verbal inflection.

The SG morpheme is unmarked in the sense that it permits both autonomous and nonautonomous plural subjects as long as they are inanimate. In this respect, the sample is closer to Persian classical prose. Even here, however, there are times SG clearly marks a nonautonomous plural subject (1a-d). Under such circumstances, SG signals a collective interpretation:

(1) Non-autonomous plural subjects (SG verbal inflection)

a. Pizza-ha-sh ma'reke-as! (S. Golshiri, 156)

pizza-PL-GEN wonderful-SG

"Pizzas here are wonderful!"

b. Asab-esh xeili xord-e. (S. Golshiri, 162)

nerves-GEN very broken-SG

"Her nerves are strained."

c. Mu-ha-ye ferdare siah-ash ruye shane va arenj-ash

hair-PL-of curly black-GEN on shoulder and elbow-GEN

rixte bud. (Xansalar, 172)

poured be-PAST-SG

"Her curly black hair was over her shoulders and elbows."

d. Chin-ha-ye damane sefid balaye zanu-ha micharxid. (Xansalar, 173)

fold-PL-of skirt white above knee-PL whirled-SG

"The folds in the white skirt were whirling around her knees."

In (1a), the speaker approaches pizzas baked in this restaurant as one single thing with the differences among them as irrelevant. Nerves in (2b) are likewise treated collectively because neither of these nerves could be singled out for straining. It is the whole nervous system that has been under pressure. In the context for (1c), neither of the black threadlike growths from the skin deserves to be treated individually. No accident that in the English translation of (1c), we treat such "hairs" as a mass noun. A similar comment may be made for "folds in the skirt" in (1d): no autonomy for either of these folds is conceivable.

For sentences marked with a PL morpheme, the pattern already detected for journalistic texts seems to dominate here, too: for inanimates conceived of as autonomous entities, the verb is inflected as plural. Examples in (2) illustrate this pattern.

(2) Autonomous plural subjects (PL verbal inflection)

a. Gahi tarjome-ha-ye motune classice Babeli vaghean yek no' some translation-PL-of texts classical Babylonian really one kind

"primitive"-budan-e andishe ra be adam montaghel-mikonand. (Bahar, p. 61) primitive-to be thinking do to man transfer-do-PL

Its history of civilization dates back to the third millennium BC. It has played a significant role in the establishment of Iranian culture and art. 
"Some translations of Babylonian classical texts imply some kind of primitiveness of thinking to the reader."

b. Mashin-ha be samt-e bala-ye xiaban dar harekat budand. (S. Golshiri, 150) car-PL to direction up-of street in movement be-PAST-PL "Cars were moving up the street."

c. Pay-ha-ye kande-shode ... amigh va tarsnak budand. (Oxovat, 194) foundation-PL-of dug deep and fearful be-PAST-PL "The holes dug in the earth were deep and fearful." (Either of them was so.)

d. Tasavir-e ghabshode-ye daryache-ha va kuha-ye sabz Pictures-of framed-of lakes and mountains-of green

va por gol-e Swiss be divar budand. (Oxovat, 196) and full flower-of Switzerland to wall be-PAST-PL

"Framed pictures of the lakes and green mountains of Switzerland were hanging on the wall."

The PL ending signals a distributive interpretation of the event. In (2a), either of these translations is understood to make the impression independently of others. So do cars in (2b). In (2c), it is either of these holes that is perceived as deep and fearful rather than their collection. Finally, the writer sees the pictures on the wall in (2d) as too different (in size, content, history, etc.) to be treated collectively. 